\title{
Teleological Contractarianism
}

\section{Introduction}

The field of animal ethics has recently taken a political turn, by which I mean that many philosophers interested in ethical questions about our treatment of nonhuman animals (hereafter referred to as "animals") have turned their attention to the issue of what the state owes to animals. A great deal of this work has been focused on the question of which, if any, obligations of justice the state has to animals. In fact, three of the most prominent instigators of the political turn-Nussbaum ${ }^{1}$, Cochrane ${ }^{2}$ and Garner ${ }^{3}$ - have focused their attention mainly on establishing that the state does indeed have such obligations and identifying their content.

Notice, however, that there are other, likewise very important, questions vis á vis the state's relation to animals that would remain open even having resolved the obligations-of-justice question. We can see this most easily by simply taking note of the consensus among liberals (to whom this essay is addressed) that much of what the state is morally obligated to do —or at least consider doing, taking into account relevant costs and other drawbacks_-for humans has nothing to do with securing justice: e.g. setting aside wild areas for recreational purposes, providing funding for the arts, establishing national holidays, etc. ${ }^{4}$

The state's obligation to do these things is based on nothing other than that doing so promotes our welfare. Promoting our welfare is one of the state's basic obligations. $^{5}$

This invites the question: Does the state have that same obligation with respect to animals? Call this the Animal Welfare Question (AWQ). Note that there is 
nothing preventing us from endorsing the Nussbaum/Cochrane/Garner claim that the state has obligations of justice to animals while denying that the state is obligated to promote the welfare of animals; answering the question of justice doesn't amount to answering the AWQ. ${ }^{6}$ To appreciate this point, consider the case of a foreign national (a human one). Even cosmopolitans, who argue that states have extensive obligations of justice to foreign nationals, don't hold that the state is obligated to promote their welfare (except insofar as promoting their welfare is part of what justice demands). Similarly, if the state has obligations of justice to the animals within its borders, this might require it to do a fair bit by way of promoting their welfare, ${ }^{7}$ but it would remain an open question whether the state could be obligated to $\varphi$ simply because $\varphi$ ing would promote the welfare of some animals within its borders. This is a more precise version — and my official version — of the AWQ.

I contend that contractarianism can give us a principled answer to the AWQ, and in this paper I will make that contention the centerpiece of an argument for contractarianism. The irony, or if not irony then at least unexpectedness, of making this argumentative move is not lost on me. For historically contractarianism, especially Rawls's version of it, has taken significant heat for implying that the state has few if any obligations to animals. ${ }^{8}$

The possibility of contractarianism having this flaw is a serious matter, but nevertheless my agenda here is to play offense as opposed to defense. ${ }^{9}$ My strategy is to show that contractarianism has an advantage in that it can give a principled answer to the AWQ while many of its competitors cannot. Contractarianism actually does give a principled answer to the AWQ, I will show, when it is formulated as teleological, where to be teleological is to attribute a purpose to the state. ${ }^{10}$ I contend that all and only teleological theories, of which I admit contractarianism is but one 
version, can give a principled answer to the AWQ. And I will argue that since contractarianism's brand of political teleology is the only metaphysically acceptable kind, we should adopt contractarianism from among the class of teleological theories. My thesis, then, is that contractarianism is pro tanto superior to other teleological theories on metaphysical grounds and pro tanto superior to non-teleological theories in its ability to give a principled answer to the AWQ.

I begin by arguing, in $\S 2$, that we have not yet been presented with a principled answer to the AWQ that doesn't appeal to the purpose of the state. This of course doesn't demonstrate that this feat cannot be pulled off; perhaps more effective non-teleological theories are yet to come. Rather, it serves the purpose of tilting the balance of considerations in favor of teleological approaches if they can succeed where non-teleological approaches haven't. Then, in $\S 3$, I show that they can indeed manage this, quite easily, and I argue that among teleological theories contractarianism is the only acceptable one that's been formulated. $\S 4$ concludes.

By way of warning, this is an essay in political philosophy, and if it qualifies in addition as an essay about animals it does so only obliquely. Crucially, this essay closes without ever defending an answer to the AWQ. This is not because of any lack of concern on my part as to what the correct answer to that question is. Just the opposite, in fact. It is because I consider that question so fundamentally important that I've arrived at the idea of arguing for contractarianism on the grounds that it, and it alone, can give a principled answer to it without succumbing to metaphysical objections. Unfortunately, giving a thorough argument for a particular answer the AWQ would require a whole essay on its own, so I cannot make my argument for contractarianism and answer the AWQ in this single piece of work. ${ }^{11}$ This may be just as well, however. Because I take no stand here as to how contractarianism, in its most 
plausible form, answers the AWQ, it is reasonable to hope that my argument for contractarianism will be assessed on its own merits since the reader's judgment of it cannot be prejudiced by her knowing my ultimate agenda vis á vis the relation between animals and the state. Of course, the drawback of this approach is that it fails to illuminate as to whether the best version of contractarianism can give a plausible answer to the AWQ, which is a shame since this is an important factor in settling whether we should accept contractarianism. But I insist that whether contractarianism can even give a principled answer at all—whatever its content-is also an important (and independent) determinant of whether we should accept it. Of course that depends on showing that the ability to do so without succumbing to metaphysical objections makes it unique among all political theories, which I do intend to show.

2. Non-Teleological Approaches to the AWQ

In this section I examine the options at our disposal for answering the AWQ in a principled way without recourse to a claim about the purpose of the state. I begin in $\S 2.1$ by assessing whether an appeal to the facts about animals' moral status can do the trick. I then devote the rest of $\S 2$ to determining whether any subfield of political theory provides tools for getting the job done, focusing initially $(\S 2.2)$ on citizenship theory before concluding $(\$ 2.3)$ by looking at democratic theory. In all three cases I will conclude that we are left without a route to a principled answer to the AWQ.

\subsection{The Appeal to Moral Status}


Perhaps the most straightforward way to approach the AWQ is to appeal to the facts whatever they are, as to whether (and if so, how much) moral status animals have. One often sees, in the literature on animal ethics, casual inferences (usually implicit) of the sort: animals do [not] have (a certain amount of) moral status and therefore the state is [not] obligated to $\varphi$ with respect to them. ${ }^{12}$

The problem with this inference is that there is a great deal of morality that floats free, more or less, from the facts about moral status and if this is true in moral theory than it may well be true in political theory as well. In moral theory, it's sensible to think that while our universal obligations_-our obligations not to lie, kill, cheat, steal, etc. - extend to all individuals with moral status, our special obligations do not. So, for instance, I have obligations of love and nurture (if I'm a parent) only to my children, I have fiduciary obligations (if I'm an attorney) only to my clients, and I have promissory obligations only to those to whom I've made promises. Similarly, there's appeal to the idea that some of the state's obligations, such as the obligation not to kill, extend to everyone with moral status (this would explain why the obligation on the part of the state to not launch wars of aggression is an obligation it has to everyone), while others of its obligations extend to only some individuals. And maybe the obligation to promote welfare is among that latter set of obligations. Those who take the nationalist side of the nationalism/cosmopolitanism debate certainly believe that the state's obligation to promote welfare is limited to those humans to whom it bears a special relationship. Of course, the nationalists might be wrong, but if they're wrong it's not simply because the humans to whom the state does not bear a special relationship have (a certain amount of) moral status. Cosmopolitans, when arguing for their view, don't simply establish that all humans have (a certain amount of) moral status and leave it at that. Rather, what both the 
cosmopolitans and the nationalists do is construct and appeal to a theory of the state's obligations.

What I'm proposing, then, is that just as it takes political theory to settle the question of whether the state has welfare-promotion obligations to the humans outside its borders, likewise it will take a political theory to answer the question whether the state has welfare-promotion obligations to the animals within its borders. This is why the appeal to moral status doesn't work as a way of answering the AWQ. For this reason, I devote the rest of $\S 2$ to examining two subfields of political theory with an eye toward determining whether they contain within them the grounds of a principled answer to the AWQ.

\subsection{The Appeal to Citizenship Theory}

Donaldson and Kymlicka devote chapters 3-5 of their book, Zoopolis, ${ }^{13}$ to an argument for domesticated animal citizenship. The claim that they devote most of those three chapters to defending and on which they base their argument for domesticated animal citizenship is:

If domesticated animals have a right that their interests count equally in determining the direction of the country then domesticated animals should be granted citizenship.

The reason Donaldson and Kymlicka devote nearly all their effort to defending this conditions is that they are worried that the idea of domesticated animal citizenship will strike the reader as preposterous. Note, however, that in order for Donaldson and Kymlicka to get anywhere by defending this conditional they need its antecedent to be true. And its antecedent cannot simply be assumed; in fact it constitutes an answer to the AWQ that many political theorists are likely to reject. Unfortunately, their 
defense of the antecedent is remarkably brief. All they say in its support is that we have "brought [domesticated animals] into our society, and deprived them of other possible forms of existence (at least for the foreseeable future)". ${ }^{14}$ So the moral premise in their argument is

1. if we have brought an individual into our society and deprived him/her of other forms of existence (at least for the foreseeable future) then that individual (if $\mathrm{s} / \mathrm{he}$ is domesticated) has a right that his/her interests help to determine the state's direction, and their empirical premise is

2. we have brought domesticated animals into our society and deprived them of other forms of existence (at least for the foreseeable future), and their conclusion is

3. domesticated animals have a right that their interests help to determine the state's direction.

Surprising as it may seem, that's pretty much it. The only thing Donaldson and Kymlicka have to add is an argument-by-analogy in favor of premise 1; specifically, they say that the case of human slaves shows that premise to be true. (For the reader who is skeptical that that could be the entirety of Donaldson and Kymlicka's argument, see their own summary of their argument. ${ }^{15}$

Premise 2 merits a close look, so we'll begin there. What do Donaldson and Kymlicka mean when they say that an individual is "in our society" and has no choice but to live out her life in it? We can hone in on an answer by examining what they say about the Amish religious community in the United States. Donaldson and Kymlicka describe them as opting out, or at least trying to opt out, of United States citizenship. Now this is not equivalent to saying that the Amish aren't "in American 
society" in the relevant sense-i.e. that a version of premise 2 concerning the Amish would be false — but surely Donaldson and Kymlicka are committed to saying just that, for two reasons. First, they come close to actually saying it when they say that the Amish are an example of a people who cannot or will not assent to the "social ethos of participation, cooperation, and affiliation". ${ }^{16}$ Second, they say that it is not inherently unfair for groups like the Amish to lack citizenship status. ${ }^{17}$ Given Donaldson and Kymlicka's further claim that citizenship is for all and only those who have "membership in a particular political community" 18 they are committed to saying that the Amish aren't members of the American political community. This isn't equivalent to saying that the Amish aren't part of American society, but it is at least close-more on this connection later.

What does the point for which I have been arguing - that Donaldson and Kymlicka are committed to saying that the Amish are not part of American societyimply for premise 2? Well if the Amish, who after all speak the same language as, engage in commerce with, and recognize the authority of most of the same laws as other Americans aren't a part of American society, it seems awfully suspect to propose a blanket categorization of domesticated animals in the United States as part of American society. Could the Amish person's horse be a member of American society while the person is not?

Of course, Donaldson and Kymlicka could make an exception for the domesticated animals that belong to members of isolationist communities such as the Amish, but that wouldn't solve the problem. For we could then ask them to point out a relevant difference between the situation of the Amish person's horse and the horse that belongs to an integrated member of American society. Surely this would be a challenge, as for both horses their life is for the most part whatever life their owner 
creates for them. Whether they have a life of hard work or leisure, whether they are given opportunities to form bonds with humans and other horses - these matters are determined by the their owner. Now this is not to say that the life of a horse isn't to some extent subject to broader societal forces. Being cut off from or integrated into society is a matter of degree, and even Amish people are somewhat integrated into broader American society, as mentioned earlier. However, to whatever extent the world of the Amish is the world they make for themselves, it is true to an even greater extent that the world of a domesticated animal is the world its owner makes for it. So since Donaldson and Kymlicka are committed to rejecting as mostly false a version of premise 2 concerning the Amish they must surely reject the original premise 2 as mostly false as well.

Having said this much, I now want to move on to critiquing premise 1, which is the more important task as regards AWQ. I contend that we should be skeptical of premise 1 because the connection between society and the state is not at all straightforward. ${ }^{19}$ Premise 1 seems to assume a tight connection, otherwise it would make no sense to say that membership in society grounds a right against the state that it allow one's interests to determine the state's direction. Now we could make premise 1 true by using the idea of the state to define society-e.g. by saying that society is that set of individuals in which the state's sovereignty resides - but then premise 1 would emerge as totally unhelpful. We can all agree that the state should advance the interests of all those that constitute its sovereign, but we will then need some guidance as to how to identify which individuals constitute the sovereign. If we instead look for an independent definition of society, we'll be in trouble for an entirely different reason, which is that "society" is a notoriously amorphous concept and consequently there are several reasonable conceptions of it. Donaldson and 
Kymlicka themselves seem torn; they implicitly appeal to a narrower one in their discussion of the Amish and then a broader one in their discussion of domesticated animals, which is what causes the just-discussed problems for premise 2. In any event, we need to know what conception of society is the politically relevant onethat is, we need to know on which conception of society it is reasonable to say that being in society entitles one to have one's interests help to determine the direction of the country. That's a question in political theory, but one with which Donaldson and Kymlicka do not engage. So although Zoopolis doesn't make the mistake of trying to answer the AWQ without appealing to political theory, its appeal to political theory doesn't go deep enough to do the trick. ${ }^{20}$

\subsection{The Appeal to Democratic Theory}

If the appeal to citizenship theory — at least the instance of it found in Zoopolis - cannot ground a principled answer to the AWQ, ${ }^{21}$ is there any other subfield within political theory that can? I'm not aware of any others having been appealed to, but to me there is an obvious candidate. This is because while there is no recognized branch of political theory devoted to answering the question of whose welfare the state is obligated to promote, there is a branch that has a closely related task: democratic theory. Among the tasks of democratic theory, it is generally agreed, is determining which individuals should be given the right to participate in democratic decision-making. Goodin calls this the problem of "constituting the demos". ${ }^{22}$ And one might think that once we've determined the composition of the demos we ipso facto have an answer to the AWQ.

This, however, is not the case. It is reasonable to think that being in a position to have one's interests set back by the state is a sufficient condition for an entitlement 
to participate in its democratic decision-making. (Goodin accepts this case. ${ }^{23}$ ) Of course, many more individuals meet this criterion than meet the criterion of being among those whose welfare the state is obligated to promote; in particular, many foreign nationals will met the former criterion but (it is generally agreed) none of them meet the latter except insofar as some amount of welfare-promotion is a requirement of justice. I'm not saying that this criterion for the constitution of the demos is valid; rather, I'm pointing out that its reasonableness shows us that answering the question of the correct constitution of the demos is not the same task as determining which individuals are such that the state ought to promote their welfare, since it is an open question whether there are sufficient grounds for an entitlement to inclusion in the demos besides being such that the state ought to promote one's welfare.

I do maintain, however, that there is a branch of political theory to which we can turn for an answer to the AWQ. The branch I have in mind is teleology - the branch of political theory devoted to determining what the state's purpose is. I turn now to explaining how political teleology can help us to discover the answer to the AWQ.

\section{The Appeal to Political Teleology}

We have seen that with respect to any given state, it might be the case that among those who possess moral status and/or are objects of duties of justice only some of them bear the right sort of special relationship to that state such that it is obligated to promote their welfare. Teleological political theories have an obvious way of capturing the idea that some individuals bear a special relation to the state and others don't: they can say that some individuals are such that the state has as its purpose 
serving their ends and others aren't. My goal in this section is to put meat on the bones of this thought.

I begin by describing how contractarianism can give a principled answer to the AWQ. Next, I identify the brand of teleology present in that kind of theory and argue that it is metaphysically innocuous in a way that other political teleologies are not. Finally, I defend that brand of teleology against objections.

\subsection{Contractarianism and the $A W Q$}

Contractarian theories, as I define that class, begin with a state of nature thought experiment. ${ }^{24}$ The state of nature is just life in the absence of a state. Often, as with Hobbes and Locke, this includes a description of the beings that live in this condition and what their lives are like. But even in the absence of such details, we are dealing with a state of nature thought experiment so long as we are invited to answer the question of whether and how a group of individuals would take action so as to avoid living in this condition.

The other classic element of a contractarian political theory is, of course, contracting. Contracting is the means by which, purportedly, the rational beings avoid the state of nature; it is the contractarian's proposed answer to the question that the state of nature thought experiment poses.

When some entity is created intentionally, that thing has as its purpose whatever its creators designed it to do. Now here's the key teleological inference that can be made: given that contracting is intentional (a safe assumption-it's too complicated to be done by accident), the thing created through this particular instance of contracting — the state — has as its purpose doing whichever thing(s) its creators design it to do. ${ }^{25}$ Of course the contractors might have designed the state to be able to 
do many things, so the contractarian should allow that the state might have many purposes, but for ease of expression I will continue to refer to 'the purpose' of the state. $^{26}$

How does contractarianism, understood as including this sort of inference, propose to answer the AWQ? (I will not discuss in this essay the versions of contractarianism that don't make this inference. ${ }^{27}$ So when I refer to 'contractarianism', I mean teleological contractarianism.) In the next sub-section I survey versions of contractarianism to illustrate how they can answer the AWQ in a principled way. (That is all I want to establish; the question of which answer is more defensible is not my concern here.)

\subsubsection{Examples}

In determining the purposes of the contractors, any contractarian theory will say something about their basic motivational outlook. At the broadest level there are three ways to describe it.

The first possibility is that the contractors are depicted as giving greatest priority to seeing that right be done, as in Christine Korsgaard's recent Kantian contractarianism..$^{28}$ In this case the contractarian will depict the contractors as creating a contract oriented to the concerns of all the different kinds of beings that matter morally, which according to Korsgaard includes some animals. Next comes the teleological inference to the claim that all the beings that matter morally are part of the state's purpose, and finally a further inference to the claim that the state is obligated to promote the welfare all the individuals that matter morally. This then serves as an answer to the AWQ. (This answer is, I think, the thesis of Korsgaard's paper, though she doesn't express it this way.) 
Second, the contractors can be depicted as not being motivated at all by moral concerns, but also as not being purely self-interested. Such versions of contractarianism will characterize the contractors as being driven by something other than morality (sympathy, perhaps) to advance the cause of some individuals but not others. Andrew Cohen, for instance, begins with the idea that parents will be concerned to protect the interests of their children, and from this starting point moves to the bolder claim that some of the contractors may well be moved to protect the interests of certain animals. ${ }^{29}$ From this premise the contractarian can make a teleological inference to the claim that the state's purpose, among other things, is to protect the interests of children and certain animals. And such a contractarian will say, in partial answer to the AWQ, that the state is obligated to promote the welfare of children and some animals.

The third possibility is that the contractors are depicted as purely selfinterested, in which case things are more complicated because there is the further question of how the contractors think about the self in which they are interested.

At one extreme we might conceive of the contractors as being situated behind an extremely thick veil of ignorance, in which case they will have a correspondingly thin conception of the self whose good they are motivated to promote. And the thinner the conception of the self, the larger the group of individuals who will fit that conception. Mark Rowlands proposes, for instance, that the veil of ignorance should exclude knowledge of species membership, in which case the contractors will agree to a contract that protects all the kinds of species that the contractors could worry that they might be members of, namely all and only the kinds of being that are sentient. ${ }^{30}$ That being the case the contractors will design the contract so as to protect all and only sentient beings, and from this premise the contractarian will infer that the state 
has the purpose of protecting all and only sentient beings. And from there it's a short step to saying in answer to the AWQ that the state is obligated to promote the welfare of all sentient animals.

At the other extreme we might depict the purely self-interested contractors as being situated behind no veil of ignorance at all. This allows them to have a full conception of their selves, and since no two individuals are identical and each contractor is purely self-interested the result we get is that the contractors share no ends at all. From this the contractarian will conclude that the contract itself is not directed toward anyone's good. This, of course, raises the question of what its content will be. One answer - and this is the answer given by Hobbes, who of course imposed no veil of ignorance on his contractors - is that the contract is nothing more than a coordinated set of rights-transfers from each individual to an artificial person, who thereby becomes the "sovereign", which for our purposes can be thought of as equivalent to the state. This being the case, the state has no positive political obligations. ${ }^{31}$ So the answer to the AWQ will be that the state is not obligated to anyone.

I'll end my survey here. My purpose has been simply to give the reader a feel for how a contractarian can answer the AWQ in a principled way. I trust that the examples already provided are sufficient to do the job.

Before closing, however, I should say something about the inference that I represented all the various kinds of contractarian, except the Hobbesian kind, as making: the inference from the state having a certain purpose to its being obligated to promote that purpose. This inference is not so obviously sound that it should be accepted without argument. Unfortunately, making that argument would require a whole other essay. ${ }^{32}$ Roughly, however, the best argument would draw on two ideas: 
1) that when an individual occupies a social role, s/he thereby acquires obligationsqua-fulfiller-of-that-role; and 2) that the role-obligations attached to any social role are determined by the purpose of that role. So, for instance, sitting on the board of directors of a corporation counts as occupying a social role - a role created for the purpose of ensuring that the goals of the corporation are met. And each member of that board therefore has a role obligation to pursue the goals of the corporation. The contractarian should say that things work roughly similarly with the state and those who occupy social roles within the state, such as legislators, judges and bureaucrats.

\subsection{The Metaphysics of Contractarianism}

With these examples on the table, I want to turn our attention briefly once again to the general form of the teleological inference that contractarians make: because the creation of the contract, and with it the state, is intentional, the state has as its purpose doing whatever the contractors designed it to do. This inference is not sui generis. We unhesitatingly make similar inferences about other abstract entities created by humans. For instance, we are happy to say that the purpose of a corporation is to do the things that its founders intended it to do. And inferences of these two sorts are actually species of a broader genus that conforms to the following template: because $\mathrm{X}$ was intentionally created it has a purpose, and its purpose is to do the thing that its designers intend(ed) it to do. ${ }^{33}$ I'll stipulate that any argument containing an inference of this sort is an instance of artifactual teleology. Contractarianism, therefore, is an instance of artifactual teleology. It says that the state is an intentionally created thing — an artifact $\mathrm{t}^{34,35}$ — that its creators are the contractors, and its purpose is whatever the contractors design it to do. ${ }^{36}$ 
Artifactual teleology shouldn't bother us any more in political theory than it does in everyday talk. Consider, for instance, a stapler. Unless we simply deny the existence of purposes, we'll be happy to say that the purpose of a stapler is to bind together sheets of paper, and that the stapler obtained that purpose on account of the fact that that was what its creators designed it to do.

So the metaphysics of artifactual teleology is entirely ordinary. To be clear, however, I am not saying that particular versions of artifactual teleology in political theory are in any way ordinary. The metaphysical commitments of artifactual teleology in political theory are entirely to do with its form, which is to say the kind of inference made, whereas any particular version of artifactual teleology in political theory is to be individuated by its premise (i.e., its state of nature story) and its conclusion (i.e. its claim as to what the purpose of the state is), and will inevitably be controversial. But the fact that the metaphysics of artifactual teleology in political philosophy is uncontroversial is crucial, because it is a central tenet of political liberalism — which, for all I have said here, may be sound - that a political theory not be based on controversial metaphysical claims. Fortunately, since artifactual teleology is metaphysically ordinary everyone should be able to agree that the state is an artifact and is therefore apt for having a purpose endowed by its creators. What reasonable people can disagree about, at least initially, is what that purpose is. But that is a political disagreement.

\subsection{Is Contractarianism Really an Instance of Artifactual Teleology?}

In $\S 3.2$ I sorted contractarianism under the genus of artifactual teleology as a way of vindicating its metaphysics. One might object, however, that I'm being too generous to contractarianism. For some artifacts, such as a stapler, we can tell a story 
about its creation that is both historically accurate and explains how it got its purpose. But the contractarian's origin story for the state is, it might be argued, a myth. So whereas the person who wants to be an artifactual teleologist about staplers is strictly bound by the facts in reasoning to her conclusion about what the purpose of a stapler is, the person who wants to be an artifactual teleologist about the state seems bound only by the limits of her imagination. For our purposes, one important result of this leeway is that contractarians will disagree, as we saw in $\S 3.1 .1$, as to the motivational profile of the contractors; they will also disagree, of course, about what the state of nature is like. Since no such contracting ever occurred, it's hard to imagine how one stipulation about the motivational profile of the contractors and the features of the state of nature could be right and all the others wrong. And since these two variables play such a central role in any contractarian's argument for a particular answer to the AWQ, it seems that the contractarian can game the system so as to support whichever answer she wants. ${ }^{37}$ Call this the arbitrariness objection.

This is an extremely serious and important worry. Notice, however, that the criticism arises insofar as one draws any substantive conclusions at all from the state of nature story. As soon as the contractarian infers that $\mathrm{X}, \mathrm{Y}$, or $\mathrm{Z}$ is true of actual states from some feature of her state of nature story, she has to contend with the accusation that that story is a myth. And all contractarians make inferences of this sort; Locke, for instance, inferred that actual states possess legitimacy only if they protect people's natural rights to life, liberty and property. The contractarian's position doesn't become any worse when she makes the teleological inference. So, to use Locke as a case study once again, Locke's position vis á vis the arbitrariness objection didn't become worse when he made the further inference that the purpose of the state is to protect people's natural rights to life, liberty and property. 
In fact, there is a way in which the contractarian's situation becomes better when she makes the teleological inference. This is because doing so puts her in a good position to answer an objection that's closely related to the arbitrariness objection—namely, the unnecessary detour objection. ${ }^{38}$ This objection begins by noting that the choice between various ways of construing the motivational profile of the contractors and other features of state of nature is obviously going to be made on moral grounds; for instance Locke's stipulation that the contractors are concerned to protect natural rights to life, liberty and property was based on his belief that there actually are natural rights to life, liberty and property. It goes on to ask why we can't simply argue for political principles directly from those moral starting points instead of taking the convoluted route of asking how contractors would reason in a state of nature modeled to account for those moral convictions. By way of response, the contractarian should admit that political principles can be established just as well without a state of nature thought experiment, but insist that the state's purpose cannot. This is because telling an artifactual story about something's purpose requires telling its origin story, which in the case of the state requires engaging in a state of nature thought experiment.

Getting back to the arbitrariness objection, as I argued already it's not the teleology of contractarianism that's causing the problem here. Therefore, I'm not going to respond to that objection here. ${ }^{39}$ As I said at the outset, my agenda is to play offense. I want to show how the particular brand of teleology that is present in contractarianism gives it an advantage over other teleological theories and also how its being teleological gives it an advantage over non-teleological theories. Other aspects of contractarianism that might constitute vulnerabilities (or strengths) are not my concern here. 


\subsection{Objections to Artifactual Teleology in Political Theory}

If sorting contractarianism under the genus of artifactual teleology is a way of vindicating its metaphysics, the next question to ask is whether this categorization could also come with a cost-Are there any drawbacks to artifactual teleology in political theory?

One obvious problem that has to be confronted when we deploy artifactual teleology in any normative field of inquiry is the problem of evil purposes. I argued in $\$ 3.1$ that there is a tight connection between the state's purpose and the fact as to what obligations it has. Well, what if the state's purpose is evil? Is it then obligated, and thus presumably permitted, to do evil?

This precise worry has been raised with respect to another kind of artifactthe corporation. ${ }^{40}$ To my mind, Kenneth Goodpaster has offered a satisfactory response to this worry. ${ }^{41}$ He says, simply, that individuals who create a corporation cannot license it to do anything that they wouldn't be morally permitted to do on their own. Goodpaster, I take it, is not denying that a corporation can have an evil purpose. Rather, he is denying that the moral constraints on the corporation are determined entirely by its purpose. He's saying that in general the ordinary moral constraints that apply to flesh-and-blood people apply to corporations too. We should concede, I suggest, that the same is true of states. Artifactual teleologists, who (by definition) want to extract at least some of their political theory from the facts as to the purpose of the state, should admit that some truths of political theory-namely, some facts about what the state is obligated to do-are simply instances of general moral facts about what all moral agents are obligated to do. ${ }^{42}$ (For instance, the state is bound by the general universal obligation not to kill.) And they should concede, further, that 
those moral facts are necessary truths and consequently set constraints on the contingent process whereby the state as artifact acquires its purpose and the corresponding obligations that follow from its having the purpose it does. This would license artifactual teleologists to concede that there are certain things the state is not permitted to do no matter what its purpose qua artifact. ${ }^{43,44}$

A second problem for artifactual teleology in political theory is that it seems that artifacts can come to have purposes that their creators did not have in mind for them. For instance, if I decide to use a t-shirt as a rag from now on, it seems that I've changed the purpose of that piece of cloth. More troublingly, a human being is an artifact and therefore, according to artifactual teleology, the purpose of a human being is whatever purpose its parents had in mind for it in creating it, regardless of any purpose that that human might set for herself. So, for instance, if a human were created for the sake of producing organs to transplant, then that human's purpose would be to provide spare parts.

Artifactual teleology clearly requires revision in light of these problems. What we should say, I think, is that anything that has a self-given purpose cannot also have a creator-given purpose. In other words, autonomy trumps artifactuality. If an individual can set an end for herself, then that's her end, period. ${ }^{45}$ And we should also allow that creator-given purposes can be trumped by new-user-given purposes, as when I repurpose a t-shirt as a rag.

Does this alter in any important way the doctrine of artifactual teleology in political theory? It does. Supposing that states are agents (as opposed to merely entities through which human agents exercise their agency), it's not plausible to deny that they're autonomous agents, since states have processes built in to them for engaging in reasoned deliberation about what to do. Furthermore, given that states 
are autonomous agents, states can give themselves purposes. Any variety of artifactual teleology in political theory will have to account for this by explaining what happens after the state is established. Contractarianism, for instance, has to entertain the possibility that the terms of the initial contract would eventually become so repugnant to the members of the state that they would come together to amend it. Having admitted for the sake of argument that states are autonomous it's not open to me to say that the intentions of the original contractors settle in perpetuity the matter of what the state's purpose is. ${ }^{46}$ What I have to say is that the intentions of the original contractors settle the matter of what the state's purpose is only if the contract they create attracts perpetual assent. ${ }^{47}$ The contractarian then has a choice to make. She can argue that her preferred contract would indeed attract perpetual assent; this would constitute an argument for what Rawls calls "stability". Alternatively, she can concede that her preferred contract would not attract perpetual assent and then undertake the task of developing a theory of how the original contract can be amended and renewed by subsequent generations. ${ }^{48}$ My suspicion is that the contractarian would do best to adopt to adopt a mixed strategy, arguing that there are certain inevitable features of our condition that can provide a rationale for perpetual assent to certain core elements of the original contract while conceding that changing circumstances provide a rationale for amending less central features of the contract.

\subsection{The Argument for Contractarianism as against Other Teleological Political}

\section{Theories}

I've been arguing in this section that contractarianism is a version of artifactual teleology in political theory and that artifactual teleology in political theory is metaphysically ordinary and not vulnerable to damaging objections. The final 
piece of the puzzle is to argue that there is no other metaphysically acceptable version of teleology in political theory.

To my knowledge there exactly two extant versions of teleology in political theory aside from artifactual teleology. One is the idea that the state has the purpose that God gives it — an idea that we find in classic natural law theories. ${ }^{49}$ This version of teleology carries the metaphysical burden of presuming the existence of a very specific sort of deity.

The other is the idea that the state has its purpose essentially, an idea we find in Plato and Aristotle. They were quite clear on the claim that the purpose of the state is to promote eudemonia, ${ }^{50}$ but they never explained why that was the state's purpose. This failure actually makes a lot of sense when taken within the context of the idea that a thing's purpose, or telos in their parlance, is an essential feature of a thing and cannot itself be explained. ${ }^{51}$ The burden carried by this sort of teleology is, of course, its teleological essentialism. It's quite counterintuitive to suppose that it could ever be the case that a thing's having a certain purpose is an unexplainable fact about it. Furthermore, if a thing's having a certain purpose were an unexplainable fact about it, it's hard to accept that that fact would have moral implications. (Whereas, by contrast, if a thing has a purpose in virtue of its creators intentionally endowing it with one, there's no mystery at all as to how this could have moral implications. We already accept that rational individuals have moral powers; that is, powers to change the moral landscape, for instance by making promises. Creating entities with purposes would simply be one more way to accomplish such changes.)

Perhaps there is some other kind of teleology in political theory that could be constructed. ${ }^{52}$ However, it is not clear that there are any unexplored options. ${ }^{53}$ Consequently we can at the very least take what I've said here as a provisional 
argument for artifactual teleology as against the other versions of teleology in political theory. Furthermore, I'm going to treat the argument I've just made as an argument for contractarianism as against all other teleological political theories, even though strictly speaking it was an argument only for artifactual teleology in political theory. This is not to suggest that contractarianism is the only possible version of artifactual teleology in political theory; it isn’t. I said in $\S 3.1$ that contractarianism has two classic elements: the state of nature thought experiment and the idea of contracting as the way to avoid the state of nature. All artifactual teleologists will agree with contractarianism that political theory must begin with state-of-nature theorizing. This is because artifactual teleology in political theory begins, by definition, with the idea that the state is to be understood as being endowed by its creators with a purpose; this means that a plausible story about its creation has to be told, which in turn means that we have to understand why rational beings would consider its existence preferable to its absence. This, in turn, requires engaging in a state of nature thought experiment. But while all artifactual teleologists must agree that the state is endowed with a purpose through its creation, they might disagree over how the state is endowed with a purpose through its creation. ${ }^{54}$ And thus some artifactual teleologists might reject the second element of contractarianismcontracting - and insert in its place some other theory about how the state of nature is purposefully avoided. Hence the possibility of a non-contractarian version of artifactual teleology in political theory.

Nevertheless, as far as I know the contracting story is the only such story that's actually been told, which means that contractarianism is the only extant version of artifactual teleology in political theory. ${ }^{55}$ As to why, I can only speculate that 
philosophers are convinced, correctly, in my judgment, that contracting is the only morally permissible way to avoid the state of nature. ${ }^{56}$

I've argued in this section that contractarianism can answer the AWQ by giving a teleological explanation of the state's having as its purpose serving the ends of some individuals and not others and inferring from the state's having that purpose that it is obligated to serve the ends of some individuals but not others. Before closing, I want to acknowledge that one might reasonably wonder why I've limited my argument for contractarianism to the claim that it can give a principled answer to the question of whether the state is obligated to promote the welfare of animals as opposed to the broader claim that contractarianism can give a principled answer to the question of whether the state is obligated to promote the welfare of $\mathrm{X}$ for any $X$. This would certainly constitute a stronger mark in contractarianism's favor, since there are other X's besides animals whose political status is controversial. We need to answer, for instance, the question whether the state is obligated to promote the welfare of human fetuses, and the question whether it's obligated to promote the welfare of severely cognitively disabled humans. If contractarianism gives us a way to develop, as I've said it does, a theory of to which individuals' ends the state is to orient itself, then it appears that contractarianism can't help but answer those questions too.

The reason I've limited my argument for contractarianism to its ability to give a principled answer to the AWQ is for lack of space. The negative part of this essay— $\$ 2$ - would have had to be much longer if I hadn't limited my ambitions this way. For then I would have had to engage with other non-contractarian literatures on the political status of various kinds of individual, such as human fetuses and severely cognitively disabled humans, to demonstrate that those literatures haven't yet 
produced a principled answer to the question whether the state is obligated to promote the welfare of those kinds of being.

\section{Conclusion}

Two of the main points for which I've argued in this essay are that teleological political theories have the resources with which to ground a principled answer to the question of whether the state is obligated to promote the welfare of its animals and that no one from the non-teleological camp has shown how we can ground a principled answer without appealing to the purpose of the state. I want to conclude by addressing the worry that I'm stirring up trouble where there need be none: one might doubt, after all, whether any heretofore anti-teleologist would care to resist the demand to attribute a purpose to the state.

I want to say two things by way of response. First, if the teleological camp within political theory, as I've described it, seems like a big tent, that's because it is. What teleologists in political theory agree about is miniscule in comparison to what they disagree about. Merely attributing the thinnest, most purely formal purpose to the state is still good enough to qualify one as an adherent of teleology in political theory.

So there's plenty of room for more theorists to join the teleological camp, and I'm happy to have the company. However-and this is my second response-I suspect that many of those who might be tempted to cross over to my side won't like the choice with which they're confronted once they do. The problem is that it's not enough just to admit that the state has a purpose; one has to take a position on why the state's purpose is what one proposes that it is. Therefore, if one doesn't want to 
endorse contractarianism one is left in the position of needing to contrive some

metaphysically acceptable story, aside from contractarianism's artifactual story, about

how a state can acquire a purpose. ${ }^{57}$ As I argued in $\S 3.5$, there doesn't seem to be any

such story to be told.

The ideas contained here were initially presented at the 2013 Polish-Scottish

Philosophy Workshop. The paper itself was presented at Studies in Social and

Political Thought (University of Sussex), the annual meeting of the European

Political Science Association, the annual meeting of the European Consortium on

Political Research, and the annual meeting of the Scots Philosophical Association. I

thank the audiences at those meetings for their helpful feedback. And I thank Lynn

Dobson, Sarah Broadie, Walter Pedriali, Julia Driver, Elie Mason and Sam Mansell

for helpful conversations on this topic. Finally, I thank David Wasserman, James

Harris, Hugh Lazenby, Cynthia Stark, Martha C. Nussbaum and Dave Wendler for

helpful feedback on previous versions of the paper.

\footnotetext{
${ }^{1}$ Martha C. Nussbaum, Frontiers of Justice (Cambridge, Mass.: Harvard University Press, 2006), Ch. 6; Martha C. Nussbaum "Beyond 'Compassion and Humanity'," in Animal Rights: Current Debates and New Directions, eds. Cass R. Sunstein and Martha C. Nussbaum (New York: Oxford University Press, 2004).

${ }^{2}$ Alasdair Cochrane, Animal Rights without Liberation (New York: Columbia University Press, 2012); Alasdair Cochrane, An Introduction to Animals and Political Theory (Basingstoke, Hampshire:

Palgrave Macmillan, 2010).

${ }^{3}$ Robert Garner, A Theory of Justice for Animals (New York: Oxford University Press, 2013).

${ }^{4}$ Two caveats: 1) In each of these cases one might argue that it's a matter of justice that the state engage in some of that activity. My point, however, is that the state morally ought to do these thingsor at least consider doing them-even if it's already done enough of them to satisfy the demands of justice. 2) One might concede that that the state has a moral reason to do these things or that there is value in the state's doing so without conceding that the state is obligated to do them. The resistance, I assume, would come from the idea that talk of 'obligations' is inapt outside the domain of justice. This is a difficult objection to refute, since philosophers use the expression 'justice' to mean so many different things, such that no definition of its domain would be uncontroversial. However, one plausible definition of justice, and the one that Nussbaum ("Beyond "Compassion and Humanity", 302) and Garner (A Theory of Justice for Animals, 48) themselves deploy, is this: the set of moral required actions each of which corresponds to a specially urgent entitlement on the part of the person to whom the action is owed. If this is what justice is, then it's simply obvious that talk of 'obligations' is apt outside the domain of justice: we can use the "obligation" label for those morally required actions that correspond with entitlements that are not specially urgent. Of course, this might be the wrong definition of justice, but in using I at least insulate myself from the charge of being unfair to Nussbaum and Garner in proposing that their respective theories of justice don't tell us everything we should want to know. This charge won't stick, because their own definitions of "justice" practically guarantee that
} 
what I'm saying about their theories of justice is true (and Garner (A Theory of Justice for Animals, Ch. 3) admits that it's true). Furthermore, if we look at the arguments Nussbaum, Cochrane and Garner muster by way of showing that the state has obligations of justice to animals, we see that those arguments are, not surprisingly, focused on showing that animals are vulnerable to particularly egregious wrongs. (Nussbaum, Frontiers of Justice, 70-1) argues that animals can be deprived of their basic entitlement to a sufficient level of each of a central list of capabilities; Cochrane (Animal Rights without Liberation) argues that animals can have their rights violated; Garner (A Theory of Justice for Animals, Ch. 2) argues that animals can be deprived of their fair share of goods.)

${ }^{5}$ Again, I will simply have to assert this without argument. For an endorsement of this idea and an attempt to render it more precise, see Daniel M. Haybron and Valerie Tiberius, "Well-Being Policy: What Standard of Well-Being," Journal of the American Philosophical Association 1, no. 4 (2015): 712-33. (And to those who deny this assertion, I want to note that it's nevertheless true that most states take themselves to have such obligations. Given this, it seems that there is a moral question as to whose welfare they should promote while they are (mistakenly) going about promoting welfare. What I say in this essay could be repackaged as an answer to that question.)

${ }^{6}$ Likewise, there is nothing stopping us from admitting that animals have rights that the state is obligated to protect while denying that the state is obligated to promote their welfare. I take it, therefore, that the large literature on whether animals have rights can be safely set aside for our purposes.

7 It certainly would if, for instance, Nussbaum's theory of justice were sound.

${ }^{8}$ See, for instance, Eva Feder Kittay, Love's Labor (Abingdon, Oxon: Routledge, 1999); Alastair Norcross, "Contractualism and the Ethical Status of Animals," Southwest Philosophy Review 17 (2000): 137-43; Robert Garner, "Rawls, Animals, and Justice: New Literature, Same Response," Res Publica 18 (2012): 159-72; Julia Tanner, "Contractarianism and Secondary Direct Moral Standing for Marginal Humans and Animals," Res Publica 19 (2013): 141-56.

${ }^{9}$ The defensive approach would be to show that contractarianism doesn't actually yield counterintuitive implications regarding the state's relationship to animals. Many philosophers have proposed amendments to or reinterpretations of Rawls's theory or contractarianism in general so as to establish a defense along these lines. (I will explain a few of them in §3.)

10 "Teleology" in the sense of purposefulness is to be distinguished from "teleology" in the sense of being oriented toward the promotion of the good.

${ }^{11}$ For one thing, it would require addressing whether the answer to the AWQ depends on the truth as to the correct theory of animal welfare and, if it turns out that it does, would require taking a stand on the correct theory of animal welfare.

${ }^{12}$ The clearest example of an argument of this sort is Julian Franklin, "Animal Rights and Political Theory," in The Oxford Handbook of the History of Political Philosophy, ed. George Klosko (Oxford: Oxford University Press, 2011). In the chapter Franklin canvasses the various contemporary theories of animal ethics, including Peter Singer's, Tom Regan's, and Christine Korsgaard's, which suggests that Franklin thinks that a theory that provides the right answers to general questions about animal rights and morally considerable interests (which is what Singer, Regan and Korsgaard each aim to provide) ipso facto provides the right answer to animal-related questions in political theory. And indeed Franklin examines the implications of the various ethical positions for questions about what kinds of animal cruelty measures should be enacted by the state. (For a succinct argument against this inference from moral status to political status - an argument with which I agree but will not make use of here-see Kimberley Smith, Governing Animals: Animal Welfare and the Liberal State (New York: Oxford University Press, 2012), Ch. 2.)

${ }^{13}$ New York: Oxford University Press, 2011.

${ }^{14}$ Ibid., 101. For a similar comment, see ibid., 100.

15 Will Kymlicka and Sue Donaldson, "Animals and the Frontiers of Citizenship," Oxford Journal of Legal Studies 34 (2014): 201-19 at 204-5.

${ }^{16}$ Zoopolis, 231.

${ }^{17}$ Ibid., 233.

${ }^{18}$ Ibid., 52.

${ }^{19}$ See Alexander Wendt, Social Theory of International Politics (Cambridge: Cambridge University Press, 1999), Ch. 5 for a discussion of the classic views regarding this relationship.

${ }^{20}$ Donaldson and Kymlicka might at this point fall back on their slavery analogy. The analogy is that just as slaves were brought from their homelands to slaveholding communities and deprived of a life outside those communities, so were previously wild animal communities domesticated and brought into human societies and deprived of a life outside them, and consequently the argument (given earlier) 
for allowing the interests of domesticated animals to determine the direction of the country is sound if the parallel argument with respect to slaves is (Zoopolis, 74, 89). The problem, however, is that the parallel argument with respect to slaves is not straightforwardly sound. Presumably when Donaldson and Kymlicka speak of allowing the interests of slaves to determine the direction of the country, they mean doing so after emancipating them, as the alternative is incoherent. But a community of emancipated slaves might have isolationist tendencies and therefore Donaldson and Kymlicka are committed to saying that a fair deal for them might involve something less than citizenship and the corresponding integration of their interests into the direction of the country, as with the Amish.

${ }^{21}$ Other citizenship theorists, by and large, simply assume without argument that citizenship is for humans only. See for instance Michael Walzer, Spheres of Justice (New York: Basic Books, 1983), Ch. 2.

${ }^{22}$ Robert Goodin, "Enfranchising All Affected Interests, and its Alternatives," Philosophy \& Public Affairs 35, no. 1 (2007): 40-68 at 40.

${ }^{23}$ Ibid.

${ }^{24}$ Since there are to my knowledge no extant theories that both contain a state of nature thought experiment and are generally categorized of as versions of contractualism, this definition of contractarianism respects the view that contractarianism and contractualism are distinct enough to merit separate discussion. For those inclined to see things this way, this essay should be read only as an argument only for contractarianism.

${ }^{25}$ Note that the inference here is not to the conclusion that the state's purpose is whatever the contract says its purpose is. Of course the contract could contain an explanation of the state's purpose, in something like a preamble. But we should allow that it might not; it could simply be an agreement to create a state that shall undertake activities $\mathrm{X}, \mathrm{Y}$, and $\mathrm{Z}$. Nor is the inference to the conclusion that the purpose of the state is to do what the contract requires it to do, since some of the things the contract requires the state to do might be mere means to some end.

${ }^{26}$ If one is uncomfortable, on metaphysical grounds, with talk of the state being an intentionally created thing and having a purpose, it is just a useful for my purposes to speak instead of the various offices of the state-legislators, judges, bureaucrats - being intentionally created things and consequently those office-holders each having a purpose.

${ }^{27}$ As it happens, in general contractarians have indeed been inclined to make this sort of inference. Kant, for instance, infers that the purpose of the state is enforcing the Right, while Locke infers that its purpose is enforcing natural rights to life, liberty and property. For further examples from earlier philosophical eras, see Otto Gierke, Natural Law and the Theory of Society, trans. Ernest Baker (Cambridge: Cambridge University Press, 1950), 113n. For an example of a contemporary philosopher making this sort of inference, see David Gauthier, "A Society of Individuals", Dialogue 55, no. 4 (2016): 601-19 esp. §7.

${ }^{28}$ Christine M. Korsgaard, "A Kantian Case for Animal Rights," in Animal Law-Tier und Recht, eds. Margot Michel, Daniela Kühne and Julia Hänni, (Zurich: Dike, 2012).

${ }^{29}$ Andrew I Cohen, "Contractarianism, Other-regarding Attitudes, and the Moral Standing of Nonhuman Animals," Journal of Applied Philosophy 24 (2007): 188-201 at 190-2. For a similar thought, see Christopher Morris, "Moral Standing and Rational-Choice Contractarianism," in Contractarianism and Rational Choice, ed. Peter Vallentyne (New York: Cambridge University Press, 1991).

${ }^{30}$ Mark Rowlands, Animal Rights: Moral Theory and Practice (Basingstoke, Hampshire: Palgrave Macmillan, 2009), Ch. 6. See also Mark Coeckelbergh, "Distributive Justice and Co-Operation in a World of Humans and Non-Humans: A Contractarian Argument for Drawing Non-Humans into the Sphere of Justice," Res Publica 15 (2009): 67-84.

It's also been proposed that the veil of ignorance should exclude the knowledge that one will always possess a sense of justice. This is another way of forcing the contracting parties to take the interests of non-humans into account. See Donald Vandeveer, "Of Beasts, Persons, and the Original Position", Monist 62 (1979): 368-77.

${ }^{31}$ Hobbes, De Cive, Chap. 7, § 9,12.

${ }^{32}$ See Benjamin Sachs, "Reversing the State of Nature Thought Experiment", unpublished manuscript.

${ }^{33}$ William Fitzpatrick, Teleology and the Norms of Nature (New York: Garland Publishing, 2001), 38, James Rachels, Created from Animals (New York: Oxford University Press, 1990), 111, and Ruth Millikan, Language, Thought, and Other Biological Categories (Cambridge, Mass.: The MIT Press, 1984), Ch. 2 explicitly endorse the practice of making inferences of this sort.

${ }^{34}$ This is an abbreviated version of Hilpinen's definition of 'artifact' in Risto Hilpinen, "On Artifacts and Works of Art," Theoria 58 (1992): 58-82. 
${ }^{35}$ The historical centrality of this idea to contractarianism is recognized in Jean Hampton, Hobbes and the Contract Tradition (Cambridge: Cambridge University Press, 1986), 273 and Gregory Kavka Hobbesian Moral and Political Theory (Princeton, N.J.: Princeton University Press, 1996), 451. Likewise, the contractarian James M. Buchanan and his co-author Gordon Tullock describe government as an artifact brought into existence to serve individuals' collective purposes in Buchanan and Tullock, The Calculus of Consent (Ann Arbor, Mich.: The University of Michigan Press, 1966), 13.

${ }^{36}$ For some important distinctions regarding artifacts and their purposes, with special attention to institutional artifacts (of which the state, on my reckoning, is one), see Kenneth M. Ehrenberg, The Functions of Law (Oxford: Oxford University Press, 2016), Ch. 2.

${ }^{37}$ This sort of criticism of contractarianism has been directed specifically at Rawls. Many theorists accuse Rawls of sneaking too much of substantive morality into his description of the original position, thus guaranteeing in an uninteresting way that his preferred principles of justice would result. See, for instance, Robert Garner, "Animals, Politics, and Justice: Rawlsian Liberalism and the Plight of Nonhumans," Environmental Politics 12 (2003): 3-22, Will Kymlicka, "The Social Contract Tradition," in A Companion to Ethics, ed. Peter Singer (Oxford: Blackwell, 1991) 193-4, David Gauthier, "Social Contract as Ideology," Philosophy \& Public Affairs 6, no. 2 (1977): 130-64 at 139n, and Russell Hardin, "Contractarianism: Wistful Thinking," Constitutional Political Economy 1, no. 2 (1990): 35-52 at 41 .

For further citations of philosophers who criticize contractarianism in this way, see Michael Lessnoff, Social Contract (Basingstoke, Hampshire: Palgrave Macmillan, 1986), 142-5.

${ }^{38}$ See, e.g., Lessnoff, Social Contract, 94 and Garner, "Rawls, Animals, and Justice," 169.

${ }^{39}$ I dedicate a whole other essay to responding to this objection. See See Benjamin Sachs, "Reversing the State of Nature Thought Experiment", unpublished manuscript.

${ }^{40}$ On the analogy between the state and the corporation, see Otto Gierke, Political Theories of the Middle Age, trans. F.W. Maitland (Bristol: Thoemmes Press, 1966) and Gierke, Natural Law and the Theory of Society, §18, F.W. Maitland, State, Trust and Corporation, eds. David Runciman and Magnus Ryan (Cambridge: Cambridge University Press, 2003), David Ciepley, "Is the U.S. Government a Corporation? The Corporate Origins of Modern Constitutionalism," American Political Science Review 111, no. 2 (2017): 418-35, and David Runciman, "Is the State a Corporation?," Government and Opposition 35 (2000): 90-104. Michael Oakeshott, who like me uses the word "artifact" to describe the state (in On Human Conduct (Oxford: Clarendon Press, 1975), Part III), also discusses this analogy.

${ }^{41}$ Kenneth Goodpaster, "Business Ethics and Stakeholder Analysis," Business Ethics Quarterly 1, no. 1 (1991): 53-73.

${ }^{42}$ One might wonder whether these general moral facts, once we incorporate them into our political theory, are sufficient for answering the AWQ. If they were then answering the AWQ wouldn't require doing political theory, and therefore the conclusion of this essay would be undermined. However, in \$2 I argued that there are no general moral facts that, when incorporated into political theory, answer the AWQ.

${ }^{43}$ The fact that some truths of political theory float free of the fact as to the state's purpose explains why some questions about what the state owes to animals don't, unlike the AWQ, hinge on the question of what the state's purpose is. Suppose, for instance, that Nussbaum and Garner are right to define 'justice' as denoting a subset of moral requirements (see footnote 1 for the relevant citations) and that those moral requirements are incumbent upon all moral agents as such. That being the case, the state's purpose, whatever it is, cannot license it to do certain things to animals-i.e. those things that would be unjust.

${ }^{44}$ Contractarians can offer this response to the problem of evil purposes only if they reject those versions of contractarianism, like David Gauthier's, that claim that the moral constraints that emerge from the contracting process are the only ones there are. I do indeed reject those versions of contractarianism, and I explain why in [citation removed for purposes of blind review]. Briefly, however, my first premise is that any action that is wrong on account of its violating the contract is a cases of non-directed wrongdoing; specifically, a case in which all parties to the contract are wronged as opposed to any one individual in particular being wronged. My second premise is that some moral wrongdoing is directed - rape, for instance. The conclusion is that some actions are wrong for a reason having nothing to do with their violating the contract.

${ }^{45}$ One might worry that this doesn't fully solve the problem, since very young children are probably not autonomous in the sense just defined. So it seems that the doctrine of artifactual teleology still yields the conclusion that the purpose of a human being can be to provide spare parts. 
By way of response, I concede the point. Note, however, that there are no unsavory ethical implications to admitting that some human's purpose is the provision of spare parts. An artifact's purpose doesn't settle the question of what the creators of that artifact are morally permitted to use it for, as I already explained in discussing the problem of evil purposes.

${ }^{46}$ Stephanie Collins and Holly Lawford-Smith, "Collectives' and Individuals' Obligations: A Parity Argument," Canadian Journal of Philosophy 46 (2016): 38-58 at 53 agree that states' purposes can change.

${ }^{47}$ This being the case, one might wonder as to the purpose of engaging in a state of nature thought experiment instead of skipping straight to the question of what purpose we are here and now conferring on the state. I argue elsewhere [citation removed for purpose of blind review] that these two possibilities aren't mutually exclusive-i.e. that the most useful version of the state of nature thought experiment treats us, here and now, as the contractors.

${ }^{48}$ See, for example, James M. Buchanan, The Limits of Liberty: Between Anarchy and Leviathan, in The Collected Works of James M. Buchanan, Vol. 7 (Indianapolis: Liberty Fund, 1975), Ch. 5 and Ryan Muldoon, Social Contract Theory for a Diverse World (New York: Routledge, 2016), Ch. 5, for the idea that the contract should be seen as in principle open to renegotiation. Insofar as the contractarian is able to make this work, she puts herself in a position to account for the fact that the most plausible real-world embodiments of the contract - the various national constitutions - are generally open to amendment. For a worry regarding contractarianism's ability to make sense of constitutional change, see Jacob T. Levy, "Not So Novus an Ordo: Constitutions Without Social Contracts," Political Theory 37 (2009): 191-217 at 209.

${ }^{49}$ E.g., Thomas Aquinas, De Regno (On Kingship) (Veritatis Splendor Publications, 2012), William of Ockham, A Letter to the Friars Minor and Other Writings, ed. Arthur Stephen McGrade and John Kilcullen, trans. John Kilcullen (Cambridge: Cambridge University Press, 1995), 291ff, and John Bramhall, The Serpent Salve, or A Remedie for the Biting of an Aspe (Ann Arbor, Mich.: Early English Books Online, 1999), last accessed 30 April 2016 at

http://gateway.proquest.com/openurl?ctx_ver=Z39.88-

2003\&res_id=xri:eebo\&rft_id=xri:eebo:image:48224.

${ }^{50}$ Plato, Republic 421b. The relevant citations for Aristotle, which I borrow from Fred Miller, “Aristotle's Political Theory," The Stanford Encyclopedia of Philosophy, ed. Edward N. Zalta, (2012) (last accessed 30 April 2016 at http://plato.stanford.edu/archives/fall2012/entries/aristotle-politics/) are Politics Book I, 1.1252a1-7 and 2.1252b29-30; Book III, 6.1278b17-24 and 9.1280b39; and Book VII, 2.1325a7-10.

${ }^{51}$ Although the ancient Greeks wouldn't have allowed that the truth about the purpose of the state can be explained, they would've allowed that it can be argued for. (Remember, Aristotle does argue for his conclusions regarding what the purposes of human beings and other living things are - see Book I of the Nicomachean Ethics.) So it's not out of place for us to speculate as to what argument Plato and Aristotle would have given for their conclusion that the purpose of the state is the promotion of human happiness. The obvious starting point for any such argument would be Aristotle's claim that the human purpose is happiness, or eudaimonia. One aspect of happiness is politicality; we are by nature political animals, in Aristotle's famous phrase (Politics, 1253a). So if the purpose of the polis were anything other than human happiness then the world itself would be disordered, which of course the ancient Greeks adamantly denied. Therefore it would be unthinkable for the purpose of the polis to be anything other than human happiness.

${ }^{52}$ I was once challenged as to how I would categorize Robert Nozick's invisible hand story of the state's creation, as found in Anarchy, State, and Utopia (New York: Basic Books, 1974), Ch. 2. I propose that it's not an instance of teleology at all. In a way Nozick's whole point in calling his story of the state's origin an 'invisible hand' story is to emphasize that the state could come into existence without anyone's intending it to (19). Of course people could later develop intentions for it, but Nozick is at pains to show that what we ought to expect of the state-namely simply that it not violate anyone's rights - is best cashed out without any reference to the state having a 'goal' (28-33). Presumably he would say the same about talk of the state's 'purpose'.

${ }^{53}$ The richest philosophical resource on functions is the literature in philosophy of biology on the functions of the features of living things. Could any of the extant theories of biological function be transposed to the political context? The capacities analysis, on which the function of a feature is determined by what it contributes to the system of which it's a part, has the disadvantage of not being able to allow for malfunction, since on this analysis if a thing fails to make a contribution then it simply has no function (Reid Blackman, "The Proper Functions of Roles and Institutions", unpublished manuscript). Surely in political theory if we're going to go in for talk of functions or purpose then we 
should want to allow for the possibility of malfunction, so as to ground potential critiques of political institutions. The other leading biological account of function, the selected effects account, holds that the function of any feature is whatever aspect of it caused that type of feature to be selected for.

Blackman has shown how a theory of this sort could work for human institutions, and consequently in principle it could stand as a competitor in political theory to the artifactual account of teleology. In practice, however, it doesn't. This is because in the case of political institution the selection in question would be social; political institutions are 'selected' only in the sense that humans create. And surely the features of political institutions that cause humans to create them are the same as the features that humans intend political institutions to have in so creating them. This being the case, the selected effects account of teleology and the artifactual account of teleology in political theory deliver the same results. Blackman, drawing on Griffiths (1993), comes close to admitting as much.

${ }^{54}$ In addition to disagreeing, of course, about what the state's purpose is.

${ }^{55}$ Granted, the theory David Hume lays out in "On the Origin of Government" is a piece of artifactual teleology (since it engages in something like a state of nature thought experiment and suggests that humans would intentionally exit the state of nature by forming a government) and is certainly noncontractarian. But it is not a political theory; in fact it is not a normative theory at all. It's merely an attempt to explain how government could come into existence and be perceived as legitimate.

${ }^{56}$ Gierke confirms that as a matter of intellectual history it was indeed this thought that led to the popularity of contractarianism. See Gierke, Natural Law and the Theory of Society, 107 and Otto Gierke, The Development of Political Theory (New York: Howard Fertig, 1966), trans. Bernard Freyd, 106.

${ }^{57}$ And if one refuses to tell a story, one is in effect saying that no story needs to be told, which amounts to endorsing essentialist teleology. 